\title{
Reform Analysis of Practical Teaching System of Mechanical Drawing Course Based on the Goal of Improving Innovation Ability
}

\author{
Xiaohao Li*

\begin{abstract}
School of Mechanical Engineering and Automation, Northeastern University, Shenyang Liaoning 110819, P.R. China
\end{abstract} \\ * Corresponding author
}

\begin{abstract}
At present, the orientation of the training goal of engineering major determines that the education process of college students is not only the teaching process of professional theory and knowledge but also the cultivation of innovative practical ability in combination with the actual situation. The main way to achieve this goal is through the practical teaching link, especially for the basic technology course of engineering major mechanical drawing course. According to the characteristics of mechanical drawing course teaching, this paper has carried out the reform of a practical teaching system to cultivate students' innovative ability. The teaching system and mode obtained from the research have been proved to be effective in practical courses, which provide an important reference for the cultivation of application-oriented talents in colleges and universities.
\end{abstract}

Keywords: Mechanical drawing, Innovation ability, Practice system

\section{INTRODUCTION}

Under the new form of engineering construction, the main training objective of undergraduate education is to train engineers who have broad professional caliber, relatively broad basic knowledge, and strong adaptability and innovative spirit, at the same time, full attention should be paid to the cultivation of innovation and practical ability. The positioning of the training goals determines that the process of college students' education is not only a process of imparting professional theories and knowledge, but also should be combined with actual training to cultivate innovative practical ability [1], which is a process of accumulation of engineering practice and work experience. The main way to achieve this goal is through practical teaching. This is especially true for engineering courses such as mechanical drawing. Know from years of engineering teaching experience, strengthening practical teaching is to improve teaching reform and improve Students' technological innovation ability.

After years of practice teaching exploration and exploration of practical operation, The Department of Mechanical Engineering of our university has gradually established and formed a practical teaching system which is in line with reality and conducive to the cultivation of talents' application ability in accordance with the national new engineering talent training model and requirements, and according to the guiding principles of thick professional foundation, practical skills and personalized training [2].

\section{CONSTRUCTION OF PRACTICAL TEACHING SYSTEM BASED ON THE ACHIEVEMENT OF TRAINING OBJECTIVES}

The practical teaching of cartography courses as a basic technical course is in a crucial position in the training of mechanical professionals [3]. Establishing a capacity-building indicator system is not only a powerful guarantee for improving teaching results but also an important means to cultivate students' practical ability and ensure teaching quality. Through the follow-up survey of graduates and the analysis of market demand for talents, the course teaching team has formulated specific targeted competence and quality indicators in accordance with the corresponding professional methods and training goals in employment, such as the ability to design and analyze mechanical products, the ability to use and maintain mechanical equipment and so on. And then we use the objectives above to guide the teaching of practice.

( i ) Set up a series of practical teaching aiming at training practical operation and application ability. Reform the existing practical teaching content of the curriculum, modify the way experiments and implement, reduce confirmatory and demonstrative experimental content, increase comprehensive and design experiments. Specify the specific requirements and assessment goals of each link separately according to the experimental characteristics.

(ii) Establish a series of practical teaching aiming at the cultivation of engineering practical ability. This link mainly 
combines the practical links of cartography courses with production practice and other practices. The feature is to encourage students to clarify the internship goals and closely follow the theoretical teaching content in practice. The target students are required to complete the prescribed tasks during the internship phase, so that the students gradually accumulate a certain engineering practice experience during the school.

(iii) Establish a series of practical teaching aiming at cultivating innovative practical ability. In the new training plan, combined with the implementation of subsequent courses in the graphics course, we have strengthened the operation content of the direction of the professional skills. In particular, the comprehensive professional practice has been added. In the subsequent undergraduate studies, students are exposed to actual design issues. There are instructors to guide graduates and graduation design at the same time. They use the issue as a link to form research groups and the development form such as collection data, collective discussion, regular answer and question, reply and comprehensive assessment have been used.

\section{BUILDING THE TEACHING ENVIRONMENT OF PRACTICE LINK BASED ON ENGINEERING ATMOSPHERE}

Judging from the teaching hardware configuration of our school's practical links in recent years, we have built and completed a number of cartographic courses and practice laboratories. Such as: cartography class mapping room, cartography class drawing room, CAD laboratory, mold design laboratory, industrial design laboratory, 3D modeling training room, innovation design laboratory, etc. At the same time, schools and departments are strengthening the construction of off-campus internship bases while improving the practice and training venues on campus. This year, our school has established good cooperative relations with many state-owned or joint-venture large enterprises such as Shenyang Machine Tool Group, Northern Heavy Industry Group, Blower Group, An Gang Group, and signed an agreement for student practice bases. By sending outstanding graduates to off-campus internship units and hiring technical personnel from relevant base units to participate in the course of practical teaching, this approach has improved the connection between the school and off-campus internship bases and ensured that engineering students have more specific and effective guidance from the practice of drawing to the practical training tasks in graduation design, which improves the quality of practical teaching.

After several years of practical teaching exploration, the course team researched and summarized the training mode of scientific research assistants, and formed a student engineering practice and scientific and technological innovation activity site composed of university students' scientific and technological innovation practice base, engineering training center, mechanical basic experimental teaching center, and advanced manufacturing technology laboratory, which has created a good atmosphere for students to practice teaching inside and outside the classroom.

\section{ESTABLISHING SCIENTIFIC MANAGEMENT SYSTEM OF PRACTICE LINK TO IMPROVE THE QUALITY OF PRACTICE TEACHING}

First of all, we must establish and improve the teaching materials and outline system of cartography courses and professional practice links, clarify the specific requirements of each practical teaching task, and design operable and easy-to-implement training content so that students have practical and objective goals $[4,5]$. After demonstrating and optimizing, some demonstrative and confirmatory experiments are appropriately eliminated, and comprehensive experiments and student-designed operation experiments are added. At the same time, change part of the experimental instruction book into a task book, let students independently design experimental methods and procedures, and use the extracurricular practice to independently develop and design, encourage students to use the experimental instruction book and related equipment in the laboratory to learn independently, help each other. Then it is to improve the practice teaching management system. The colleges and grass-roots teaching and research offices have set up teaching reform teams. Through the establishment of the practice teaching reform project, they formulate the quality standards for practice teaching, the laboratory opening system, additional points for innovative design experiments, and innovative practice activities. Management measures guide the reform of practical teaching, and check and guide the teaching process.

While exploring and reforming practical teaching links, the course teaching team also optimized and rationally arranged the theoretical teaching and practical teaching arrangements of cartographic courses in stages, focusing on a number of follow-up professional courses that are closely integrated with practical teaching links. With the advancement of teaching reform, courses such as cartography, mechanical principles, and mechanical design have been established as key construction courses. The classroom teaching and experimental teaching are closely organized in a teaching plan. The content of the theoretical course is to teach basic knowledge and cultivate practical ability. The practice room advocates intensive lecture and practice, and applies basic theoretical analysis as much as possible to solve practical problems. When arranging teaching, the theoretical teaching part is scheduled first. The experiments are opened by the laboratory according to the course progress. Through the corresponding management system and the guidance and guidance of professional instructors, the premise of students having spare time is as much as possible. Those who are 
connected with each other, complement each other, and promote each other, and jointly support the realization of the goal of talent training.

\section{CONSTRUCTION OF MEASURES TO STIMULATE STUDENTS' ENTHUSIASM IN PRACTICAL OPERATION}

In the course of practical teaching of cartography courses, the instructors should pay attention to stimulating students' interest in practical operation, discovering students' practical innovations for security, training students' desire for knowledge, and creating a good style of study. Require teachers in the course of teaching to be specifically organized to facilitate student learning. The development of syllabuses and the compilation and selection of teaching materials should be based on the starting point and goals of students. Integrate into the experiment, so that students can really ask questions, solve problems, and strengthen practical skills in the experiment. In the innovative experiments, the teachers of the course only put forward the requirements of the practical goals in the early stage of the implementation of the practical link. The specific experimental principles and steps exercised the students to complete independently and independently, and created conditions for students to actively think and actively explore. By setting up independent practice teaching links, students are encouraged to improve their practical ability and enthusiasm for active learning $[6,7]$.

It is necessary for students to make full use of their spare time, to explore and promote the training mode of scientific research assistants, to encourage personalized training, and to encourage students to obtain innovative credits stipulated in the training program by participating in various meaningful activities, and to encourage students to assist teachers in participating in the construction of practical links. Participate in the daily management of the laboratory, while encouraging students with sufficient ability to moderately participate in scientific research projects, and strengthen their ability to practice and innovate.

\section{STRENGTHEN THE EXAMINATION OF PRACTICAL TEACHING LINKS TO IMPROVE TEACHING QUALITY}

Teachers who organize the curriculum team need to strictly implement the practice evaluation link, infiltrate the ability training into various practice links, and evaluate the student's practice effectiveness according to the quality standards and ability indicators of school practice, experiment, and practice teaching. The assessment adopts a combination of real-time assessment and comprehensive assessment. It focuses on the deepening of theoretical knowledge and skills and the cultivation of comprehensive application capabilities, and strictly adopts the application-oriented talent capacity training indicators as the standard. When setting up the students' curriculum design questions, the teachers of the courses should, according to the actual situation of the students, combine their topic selection requirements with practical applications, preferably from actual projects in production engineering, and discuss the solutions in groups. Evaluating results is a quantitative assessment based on the workload, difficulty, level and practicability of the results provided by the student upon completion. Implementation of the graduation design for the final student exit requires students to pass the preliminary practical learning and have the assessment index requirements to solve the actual engineering problems. It is necessary to strengthen the goal setting of the graduation design, emphasize the comprehensive application ability of students, and at the same time diversify the graduation topics, and strive to be beneficial to the students' comprehensive use of the theoretical knowledge and skills exercise, and encourage students to prepare their own topics based on the subject competitions that they will partake. All settings are set up to help students develop the ability to think independently and dare to innovate. In these aspects, instructors are required to strictly control quality in all aspects, including topic selection, guidance, and review.

\section{SUMMARY}

Based on the characteristics of descriptive geometry and mechanical drawing courses, this article carries out an analysis of the reform of the practical teaching system to cultivate students' creative ability; We have explored the practical links of reform and implementation of cartography courses, strengthened the practice topic selection, operation management, evaluation, and assessment, and completed the cultivation of college students' innovative abilities in all majors of engineering. It can be seen from the reform process that the important guarantee for the cultivation of innovative talents in the rational construction of a practical teaching system plays an important and irreplaceable role in promoting the construction of students' academic style and improving their innovative capabilities. The application of the teaching system and model obtained in the research in the actual course practice has shown that it is fruitful and provides important reference and reference for the cultivation of applied talents in various universities.

\section{ACKNOWLEDGEMENT}

This research was supported by Education and Teaching Reform Project of Liaoning Province, China (No. [2018] 471 Letter from Liaoning Education Department) and Education and Teaching Reform Project of Northeastern University of China (No. [2018] 39 Teaching 
Documents of Northeastern University).

\section{REFERENCES}

[1] $\mathrm{L} . \mathrm{Xu}$, Relevant reflections on the cultivation of innovative mechanical design ability of mechanical engineering students, Sci. Educ. Artic. Collect. 12 (2017) 50-51.

[2] L. Li, H.D. Wu, S.M. De, Stressing the cultivation of creative design ability in the teaching reform of mechanical drawing, High. Educ. Sci. 01 (2008) 137-140.

[3] L.C. Ning, Y.M. Xie, L. Xiao, Y. Zhou, Research on the reform of mechanical drawing courses integrated with information technology, Gu. Sci. Educ. 10 (2018) 71-73.

[4] B. Li, W. Xu, Discussion on the teaching reform of mechanical drawing course for the training of excellent engineers, Univ. Educ. 13 (2013) 127-128.

[5] S.W. Wang, Research and practice of creative thinking teaching in engineering graphics, J. Archit. Educ. Inst. High. Learn. 05 (2013) 81-84.

[6] W.J. Ge, Research and practice on teaching reform of mechanical Basic Courses, J. Northwest. Polytech. Univ. (Soc. Sci.) 03 (2003) 83-85.

[7] Z.B. Gao, Y.F. Qin, J. Zhang, S.Q. Chen, Engineering graphics teaching reform for excellence program, Equip. Manu. Tech. 09 (2014) 283-285. 